\title{
Opioid receptor-triggered spinal mTORC1 activation contributes to morphine tolerance and hyperalgesia
}

\author{
Ji-Tian Xu, ${ }^{1,2}$ Jian-Yuan Zhao, ${ }^{1}$ Xiuli Zhao, ${ }^{1}$ Davinna Ligons, ${ }^{1}$ \\ Vinod Tiwari, ${ }^{1}$ Fidelis E. Atianjoh, ${ }^{1}$ Chun-Yi Lee, ${ }^{1}$ Lingli Liang, ${ }^{1,3}$ Weidong Zang, ${ }^{1,2}$ \\ Dolores Njoku, ${ }^{1}$ Srinivasa N. Raja, ${ }^{1}$ Myron Yaster, ${ }^{1}$ and Yuan-Xiang Tao,,3
}

\begin{abstract}
${ }^{1}$ Department of Anesthesiology and Critical Care Medicine, Johns Hopkins University School of Medicine, Baltimore, Maryland, USA. 2Department of Neurobiology, College of Basic Medicine, Zhengzhou University, Zhengzhou, Henan Province, People's Republic of China. ${ }^{3}$ Department of Anesthesiology, New Jersey Medical School, Rutgers, The State University of New Jersey, Newark, New Jersey, USA.
\end{abstract}

\begin{abstract}
The development of opioid-induced analgesic tolerance and hyperalgesia is a clinical challenge for managing chronic pain. Adaptive changes in protein translation in the nervous system are thought to promote opioid tolerance and hyperalgesia; however, how opioids drive such changes remains elusive. Here, we report that mammalian target of rapamycin (mTOR), which governs most protein translation, was activated in rat spinal dorsal horn neurons after repeated intrathecal morphine injections. Activation was triggered through $\mu$ opioid receptor and mediated by intracellular PI3K/Akt. Spinal mTOR inhibition blocked both induction and maintenance of morphine tolerance and hyperalgesia, without affecting basal pain perception or locomotor functions. These effects were attributed to the attenuation of morphine-induced increases in translation initiation activity, nascent protein synthesis, and expression of some known key tolerance-associated proteins, including neuronal NOS (nNOS), in dorsal horn. Moreover, elevating spinal mTOR activity by knocking down the mTOR-negative regulator TSC2 reduced morphine analgesia, produced pain hypersensitivity, and increased spinal nNOS expression. Our findings implicate the $\mu$ opioid receptor-triggered PI3K/Akt/mTOR pathway in promoting morphine-induced spinal protein translation changes and associated morphine tolerance and hyperalgesia. These data suggest that mTOR inhibitors could be explored for prevention and/or reduction of opioid tolerance in chronic pain management.
\end{abstract}

\section{Introduction}

Chronic pain is a major public health problem. About 116 million Americans (approximately $30 \%$ of the population) live with this disorder. The economic impact of chronic pain is equally large, at around $\$ 100$ billion annually (1). Although recent advances have been made in the therapeutic management of chronic pain, opioids are still the gold standard for its pharmacological treatment in the clinical setting. However, long-term use of these drugs is often limited by the development of analgesic tolerance and hyperalgesia, phenomena observed in both laboratory animals and patients (2). Opioid tolerance is characterized by a progressive lack of response to opioids that can be overcome by escalating doses to achieve equivalent pain relief. In contrast, opioid-induced hyperalgesia is a sensitization process in which opioids paradoxically produce pain hypersensitivity. These undesirable manifestations, along with other adverse effects caused by escalating doses (e.g., oversedation, respiratory depression, and constipation), significantly decrease quality of life in patients with chronic pain.

Despite intensive research into the neurobiological mechanisms of opioid-induced tolerance and hyperalgesia in the past decades, opioid-induced tolerance and hyperalgesia are still ineffectively managed by current drugs, in part because these drugs target a single mechanism and/or produce several side effects. It is well docu-

Authorship note: Ji-Tian Xu, Jian-Yuan Zhao, and Xiuli Zhao contributed equally to this work.

Conflict of interest: The authors have declared that no conflict of interest exists. Citation for this article: J Clin Invest. 2014;124(2):592-603. doi:10.1172/JCI70236 mented that repeated and long-term exposure to opioids causes opioid receptor-mediated adaptive changes within the nervous system, including desensitization, internalization, downregulation, and phosphorylation of opioid receptors (3) or heterodimerization with other receptors (4). Moreover, chronic opioid exposure leads to adaptive changes in different neuronal circuits, including activation of anti-opioid systems (e.g., excitatory neurotransmitter release from primary afferents and spinal dorsal horn glutamate receptor activation; descending spinal facilitation; glial cell activation and cytokine release; and upregulation of dorsal horn neuronal NOS [nNOS], PKC $\gamma$, and CaMKII $\alpha$ ) (5-9). All of these changes likely occur via translational modulation of many individual proteins, counteract opioid analgesia, and contribute to the mechanisms of opioid-induced tolerance and hyperalgesia. However, the intracellular processes that initiate the translation of multiple proteins after opioid stimulation remain elusive.

Mammalian target of rapamycin (mTOR), a serine-threonine protein kinase, forms 2 distinct protein complexes, mTOR complex 1 (mTORC1) and mTORC2. mTORC1, which is composed of raptor, mLST8, and mTOR, is classically known to gate translation of most proteins by phosphorylation of specific downstream effectors, such as the eukaryotic initiation factor $4 \mathrm{E}$-binding (eIF4E-binding) proteins (4E-BPs) and $\mathrm{p} 70$ ribosomal $\mathrm{S} 6$ protein kinases (S6Ks) (10). mTOR, S6K1, and 4E-BP1 are expressed in the mammalian nervous system, particularly in spinal cord dorsal horn (11). Because dorsal horn is strongly implicated in the generation of opioid tolerance and hyperalgesia (12), we postulated that dorsal horn mTOR might be a key player in opioid-induced 
adaptive changes that occur in protein translation and contribute to the development and maintenance of opioid-induced tolerance and hyperalgesia.

\section{Results}

Inbibiting $m T O R$ prevents the development of morphine-induced tolerance and byperalgesia. Because morphine is an opioid often used in pain management, we used preclinical animal models of morphineinduced tolerance and hyperalgesia. We first examined whether blocking spinal mTOR affected the development of morphine tolerance and hyperalgesia by pretreating rats with an intrathecal injection of rapamycin, a specific and selective inhibitor of $\mathrm{mTOR}$ activity in mTORC1 (but not in mTORC2) (13). Ascomycin, which does not inhibit mTOR activity, was used as a negative control (13). Repeated, twice-daily intrathecal injections of $10 \mu \mathrm{g}$ morphine for 6 days led to a time-dependent decrease in morphine's maximal potential analgesic effect (MPAE). MPAE on days 3, 5, and 7 was reduced $2 \%(P>0.05), 73.2 \%(P<0.01)$, and $98.3 \%(P<0.01)$, respectively, from day 1 (Figure 1A). Repeated intrathecal morphine injections also produced a rightward shift in the cumulative doseresponse curve of morphine on day 7 (Figure $1 \mathrm{~B}$ ). The $\mathrm{ED}_{50}$ value of morphine was $0.67 \mu \mathrm{g}$ in vehicle plus saline-injected controls and $16.08 \mu \mathrm{g}$ in the morphine plus vehicle-treated group (Table 1). The reduction in morphine's MPAE was significantly prevented by once-daily coadministration of $10 \mu \mathrm{g}$ rapamycin, but not $10 \mu \mathrm{g}$ ascomycin (Figure 1, A and B). In the rapamycin plus morphine-treated group, MPAE decreased $48.4 \%$ and $\mathrm{ED}_{50}$ was $1.97 \mu \mathrm{g}$ on day 7 (Figure $1 \mathrm{~A}$ and Table 1 ). The effect of rapamycin was dose dependent (Figure 1C). These observations cannot be explained by direct interaction between rapamycin and morphine, because rapamycin at a submaximal dose did not alter morphine analgesia in naive rats (Figure 1D). Rapamycin alone did not change basal tail flick response to thermal stimulation (Figure 1, A, B, and D). Neither rapamycin nor ascomycin altered locomotor function (Supplemental Table 1; supplemental material available online with this article; doi:10.1172/JCI70236DS1).

Consistent with previous reports (14), 6 days of repeated intrathecal morphine injections induced bilateral mechanical and thermal pain hypersensitivities on day 7. Paw withdrawal thresholds in response to mechanical stimuli were reduced $74.5 \%$ and $73.5 \%$ in left and right hind paws, respectively, in the morphinetreated versus the control group (both $P<0.01$; Figure $1 \mathrm{E}$ and Supplemental Figure 1A). Similarly, paw withdrawal latencies in response to thermal stimuli were reduced $19.1 \%$ and $22.7 \%$ in left and right hind paws, respectively, in the morphine-treated versus the control group (both $P<0.05$; Figure $1 \mathrm{~F}$ and Supplemental Figure 1B). These reductions were completely abolished by coadministration of $10 \mu \mathrm{g}$ rapamycin, but not by $10 \mu \mathrm{g}$ ascomycin, on

\section{Table 1}

Effect of rapamycin on morphine tolerance

\begin{tabular}{lcc} 
Group & $\mathbf{5 0} \%$ analgesic dose $(\mu \mathbf{g})$ & $\mathbf{9 5} \% \mathbf{C l}(\mu \mathbf{g})$ \\
Vehicle plus saline & 0.67 & $0.05-1.28$ \\
Vehicle plus saline & 0.99 & $0.56-1.42$ \\
Vehicle plus morphine & 16.08 & $15.81-16.35$ \\
Ascomycin plus morphine & 15.76 & $15.36-16.16$ \\
Rapamycin plus morphine & 1.97 & $1.00-2.94$ \\
\hline
\end{tabular}

$n=6-7$ per group. day 7 (Figure 1, E and F, and Supplemental Figure 1, A and B). Rapamycin alone did not alter basal paw withdrawal responses to mechanical and thermal stimuli (Figure 1, E and F, and Supplemental Figure 1, A and B).

Inbibiting $m$ TOR reduces established morphine tolerance and byperalgesia. We also investigated the role of mTOR in the maintenance of morphine tolerance and hyperalgesia. Rapamycin and ascomycin were administered intrathecally (each $10 \mu \mathrm{g}$ daily) beginning on day 7 (a time point at which morphine tolerance and hyperalgesia were fully established) of an 11-day course of morphine injections. Rapamycin, but not ascomycin, markedly reversed morphine-induced decreases in MPAE, paw withdrawal thresholds, and paw withdrawal latencies during the maintenance period (Figure 1, G-I, and Supplemental Figure 1, C and D). On day 12, MPAE increased 70.2\% $(P<0.01)$, paw withdrawal thresholds increased 4.6- and 5.8-fold in left and right hind paws, respectively (both $P<0.01$ ), and paw withdrawal latencies increased $16 \%$ and $17.4 \%$ in left and right hind paws, respectively (both $P<0.05$ ), in the rapamycin-treated versus the vehicle-treated group.

Inbibiting mTOR does not produce immune-related side effects. Rapamycin is used clinically as an immunosuppressive drug (15). To determine whether the doses of rapamycin used produced immune-related side effects, we collected spleens from rats that received intrathecal injections of $10 \mu \mathrm{g}$ rapamycin or vehicle daily for 6 days. Time-dependent, concanavalin A-stimulated (ConAstimulated) $\mathrm{T}$ cell proliferation was similar in the vehicle- and rapamycin-treated groups (Figure $1 \mathrm{~J}$ ). In addition, no significant differences were found in splenocyte number, spleen weight, body weight, or blood parameters between the vehicle- and rapamycintreated groups (Supplemental Table 2).

Spinal mTOR knockdown blocks the development of morphine-induced tolerance and hyperalgesia. To further confirm our pharmacological observations, we examined whether spinal mTOR deficiency affects induction of morphine tolerance and hyperalgesia. Intrathecal injection of $5 \mu \mathrm{g}$ mTOR siRNA knocked down spinal mTOR expression, but did not alter expression of other proteins, such as PSD-95 and the 2 downstream effectors of mTOR, S6K1 and 4E-BP1 (Figure 2A). mTOR level was $60 \%$ less in the siRNAtreated group than in the vehicle-treated group (Figure 2A). Like rapamycin, mTOR siRNA dramatically blocked morphineinduced decreases in MPAE and paw withdrawal thresholds and latencies (Figure 2, B-F). Control, scrambled mTOR siRNA had no effect on spinal mTOR expression or morphine-induced tolerance and hyperalgesia (Figure 2). Neither mTOR siRNA nor scrambled mTOR siRNA alone affected basal mechanical or thermal responses or locomotor function (Figure 2, B-F, and Supplemental Table 1). Taken together, the results of our behavioral studies indicated that spinal mTOR activity may be required for the development and maintenance of morphine tolerance and hyperalgesia.

mTOR activation in dorsal horn neurons after repeated intrathecal morphine injections. Our behavioral observations suggest that spinal mTOR is activated during chronic morphine exposure. To test this possibility, we next examined the phosphorylation levels of mTOR, S6K1, and 4E-BP1 in dorsal horn and dorsal root ganglion (DRG) after repeated morphine injections. Consistent with previous reports (11), phosphorylated mTOR (p-mTOR), p-S6K1, and p-4E-BP1 were undetectable or expressed at low levels in dorsal horn of naive and saline-treated rats. Intrathecal morphine caused significant, timedependent increases in p-mTOR, p-S6K1, and p-4E-BP1 levels in lumbar enlargement segments, but not in thoracic and cervical segments 


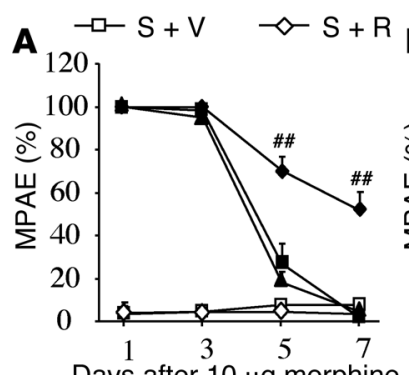

Days after $10 \mu \mathrm{g}$ morphine E or saline injection (twice a day)
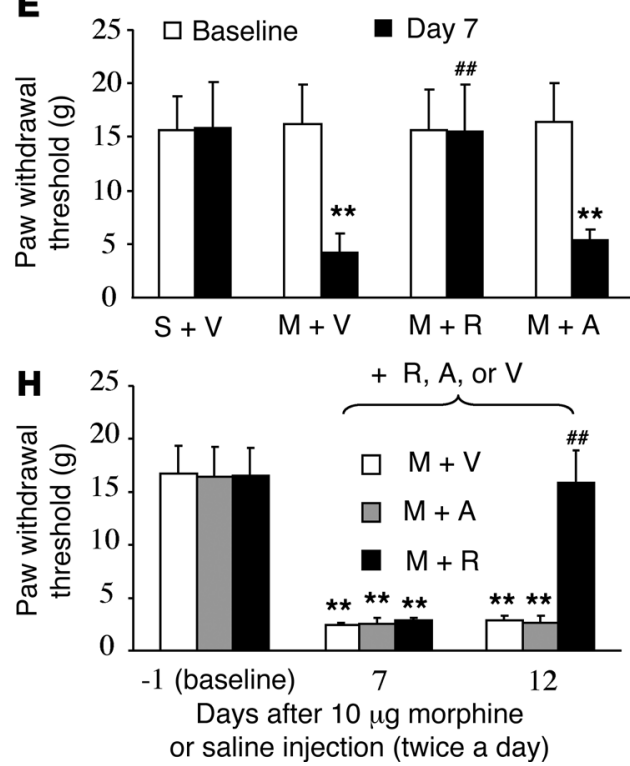

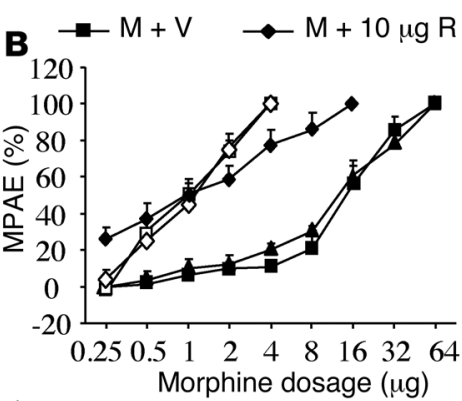

$\mathbf{F}$

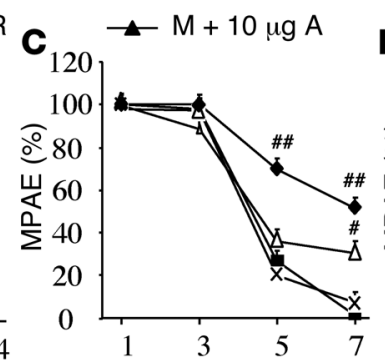

Days after $10 \mu \mathrm{g}$ morphine or saline injection (twice a day)

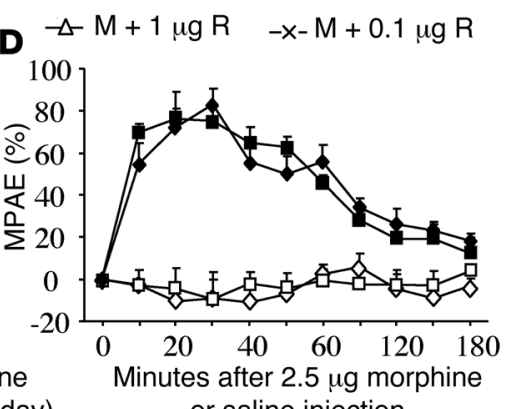

or saline injection
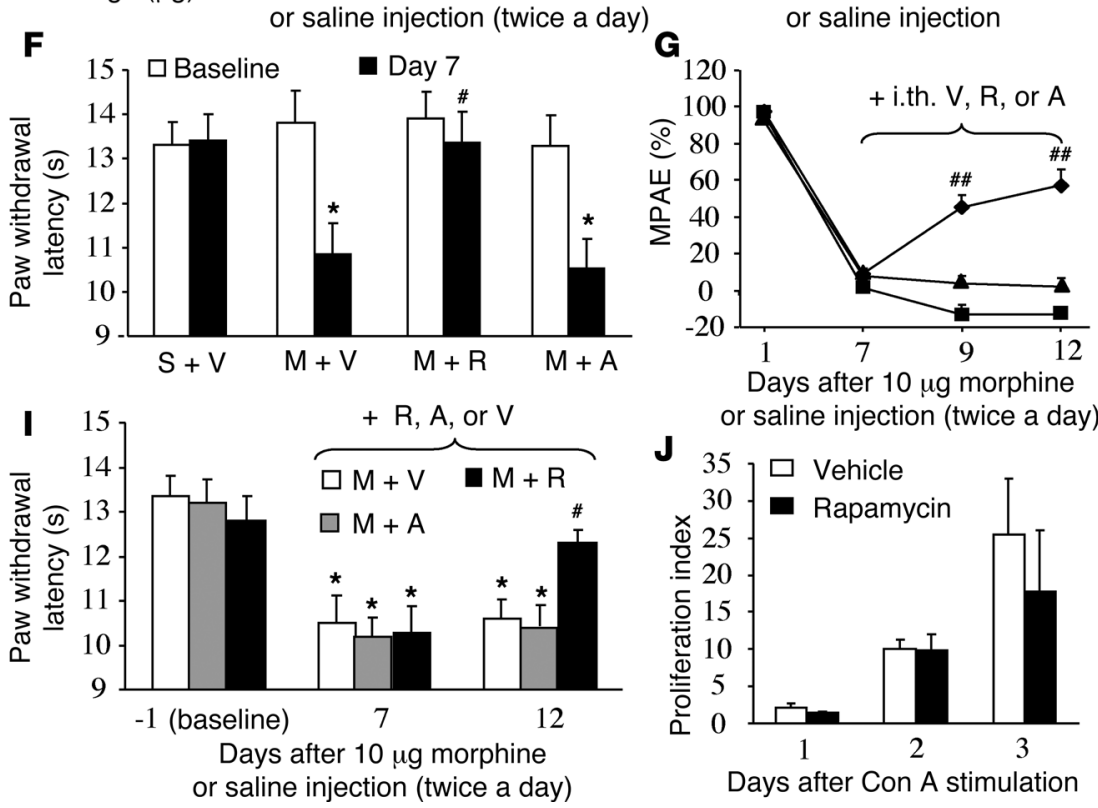

Figure 1

Intrathecal rapamycin attenuates the development and maintenance of morphine tolerance and hyperalgesia. $n=5-7$ rats per group. (A-C) Morphine (M) was administered intrathecally twice daily for 6 days. (A) Rapamycin $(R)$, but not ascomycin $(A)$, attenuated the reduction in morphine's maximal potential analgesic effect (MPAE) on days 5 and 7. S, saline; V, vehicle. (B) Rapamycin, but not ascomycin, blocked a rightward shift in the cumulative dose-response curve of morphine on day 7. (C) Rapamycin dose-dependently attenuated the reduction in morphine's MPAE on days 5 and 7. (D) Coinjection of rapamycin did not affect analgesia induced by a submaximal dose of intrathecal morphine. (E and $\mathbf{F}$ ) Morphine was administered intrathecally twice daily for 6 days. Coadministration of rapamycin, but not ascomycin, blocked morphine-induced decreases in left hind paw withdrawal threshold $(\mathbf{E})$ and latency $(\mathbf{F})$ on day 7. (G-I) Morphine was administered intrathecally twice daily for 11 days. (G) Coadministration of rapamycin beginning on day 7 reversed morphine-induced reductions in MPAE on days 9 and 12 . $n=5-6$ rats per group. ( $\mathbf{H}$ and $\mathbf{I})$ Coadministration of rapamycin beginning on day 7 reversed the reductions in left hind paw withdrawal threshold $(\mathbf{H})$ and latency $(\mathbf{I})$ on day 12. (J) Concanavalin A-stimulated (ConA) proliferation of splenocytes and effect of rapamycin pretreatment. ${ }^{*} P<0.05$, ${ }^{* \star} P<0.01$ vs. baseline; ${ }^{\#} P<0.05, \# P<0.01$ vs. morphine plus vehicle.

(Figure 3A and Supplemental Figure 2). Total expression of mTOR, $\mathrm{S} 6 \mathrm{~K} 1$, and 4E-BP1 protein in dorsal horn was not altered during the observation period (Figure 3B). Furthermore, the number of cells positive for p-mTOR, p-S6K1, and p-4E-BP1 was dramatically increased in the dorsal horn (Figure 3C). These increases occurred exclusively in dorsal horn neurons, as staining of these 3 phosphorylated proteins overlapped that of the neuronal marker NeuN, but not that of the astrocyte marker GFAP or the microglia marker OX-42 (Figure 3D). No changes in p-mTOR, p-S6K1, and p-4E-BP1 levels were observed in left or right lumbar DRGs (Supplemental Figure 3).

$\mu$ opioid receptor-dependent spinal $m$ TOR activation during chronic morphine exposure. Morphine binds predominantly to the $\mu$ opioid receptor, but it also binds weakly to $\kappa$ and $\delta$ opioid receptors (16). Hence, we sought to determine which opioid receptors trigger morphine-induced activation of mTOR and its downstream effectors in dorsal horn neurons, using a spinal dorsal horn neuronal culture model. We challenged cultured neurons with morphine and various opioid receptor antagonists. Morphine stimulation did not alter total expression of mTOR, S6K1, and 4E-BP1, but time- and dosedependently increased their phosphorylated counterparts (Supplemental Figure 4). These increases were attenuated by coadministration of the nonselective opioid receptor antagonist naltrexone and the selective $\mu$ opioid receptor antagonist CTOP, but not the selective $\kappa$ opioid receptor antagonist $\eta$-BNI or the selective $\delta$ opioid receptor antagonist naltrindole (Figure 4, A and B, and Supplemental Figure 5). Administered alone, these antagonists did not change basal levels of p-mTOR, p-S6K1, or p-4E-BP1 (Figure 4, A and B, and Supplemental Figure 5). DAMGO, a selective $\mu$ opioid receptor agonist, produced effects similar to those of morphine (Figure 4C and Supplemental Figure 6). 

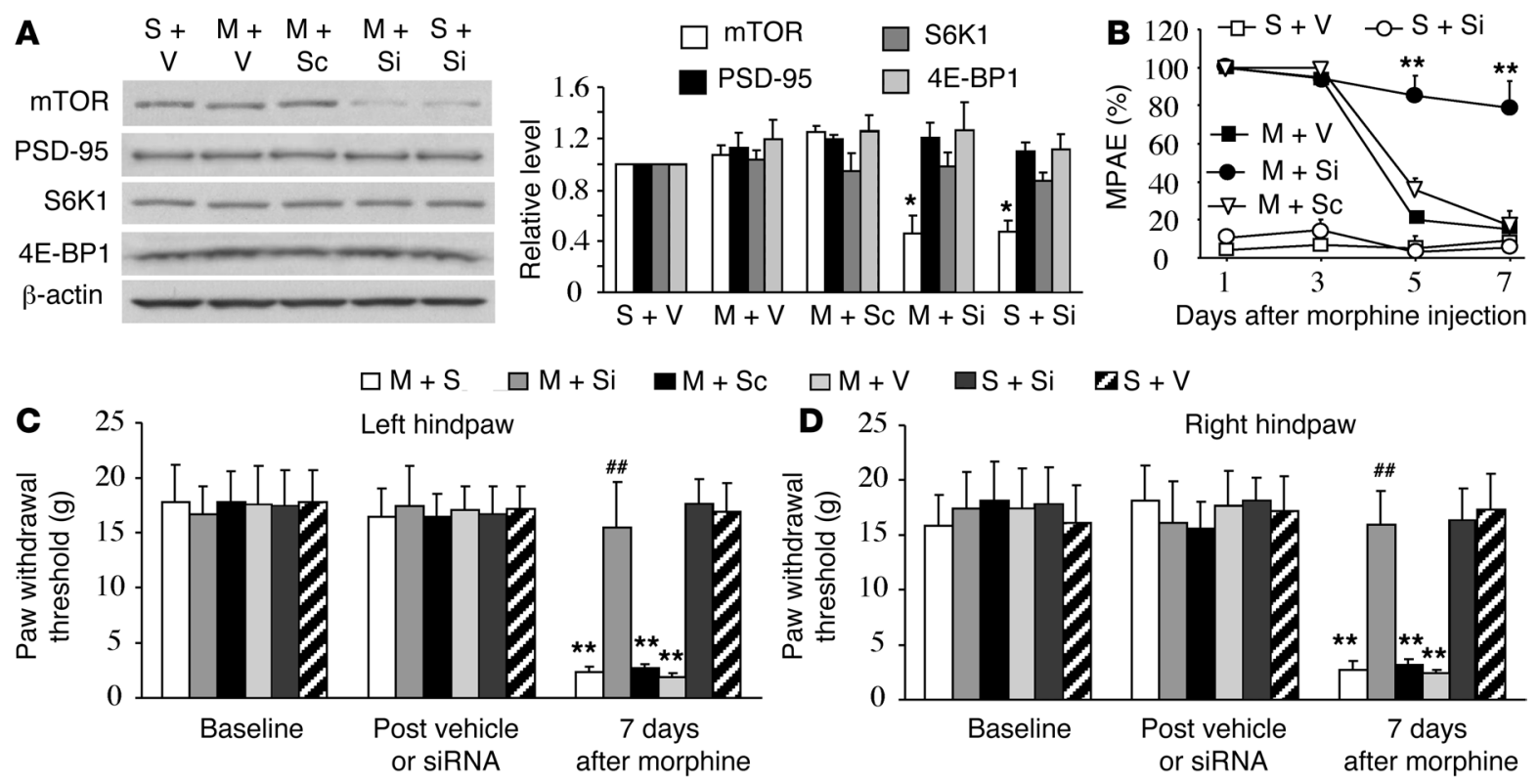

$\mathbf{Z S}+\mathrm{V}$
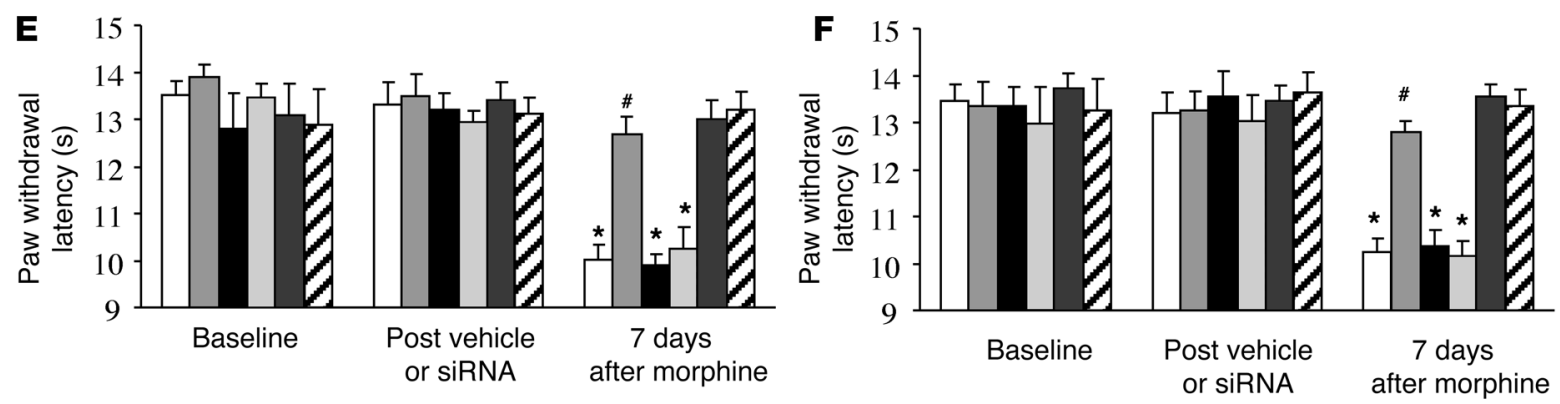

Figure 2

Spinal mTOR knockdown attenuates the development of morphine-induced tolerance and hyperalgesia. (A) Intrathecal mTOR siRNA $(\mathrm{Si}, 5 \mu \mathrm{g})$, but not mTOR scrambled siRNA (Sc, $5 \mu \mathrm{g}$ ), significantly reduced expression of mTOR without affecting expression of PSD-95, S6K1, or 4E-BP1 in dorsal horn. Representative Western blots and summary of densitometric analysis (normalized to $\beta$-actin loading control) are shown. ${ }^{\star} P<0.05$ vs. saline plus vehicle. $n=5$ rats per group. (B) Intrathecal mTOR siRNA, but not mTOR scrambled siRNA, dramatically blocked the morphine-induced decrease in MPAE on days 5 and 7 of twice-daily intrathecal morphine injections. ${ }^{\star \star} P<0.01$ vs. morphine plus vehicle. $n=5$ rats per group. (C-F) Intrathecal mTOR siRNA, but not mTOR scrambled siRNA, markedly blocked morphine-induced decreases in left (C and $\mathbf{E}$ ) and right ( $\mathbf{D}$ and $\mathbf{F})$ hindpaw withdrawal thresholds in response to mechanical stimuli $(\mathbf{C}$ and $\mathbf{D})$ and withdrawal latencies in response to thermal stimuli (E and F) after 7 days of twice-daily morphine injections. ${ }^{*} P<0.05,{ }^{* \star} P<0.01$ vs. baseline; ${ }^{\#} P<0.05$, ${ }^{\# \#} P<0.01$ vs. morphine plus saline. $n=5$ rats per group.

An important advantage to using an in vitro cell culture model is the simplicity with which it provides direct evidence that $\mu$ opioid receptor activation activates $\mathrm{mTOR}$ and its downstream effectors in dorsal horn neurons. However, the models may not reflect real processes that occur in vivo. To overcome this obstacle, we examined the effect of spinal $\mu$ opioid receptor inhibition on morphine-induced activation of spinal mTOR and its downstream effectors in vivo. Intrathecal coinjection of CTOP not only attenuated morphine-induced decreases in MPAE and paw withdrawal threshold (Supplemental Figure 7, A-C), but also blocked morphine-induced increases in p-mTOR, p-S6K1, and p-4E-BP1 in dorsal horn (Figure 4D). CTOP alone had no effect on basal level of the 3 phosphorylated proteins (Figure 4D). Furthermore, mice with knockout of $\mu$ opioid receptor failed to display an analgesic effect or an increase in dorsal horn p-mTOR after repeated subcutaneous injections of morphine (Figure 4E and Supplemental Figure 7D). Double labeling revealed that $\mu$ opioid receptor mRNA coexpressed with $\mathrm{mTOR}$ and morphineinduced p-mTOR in dorsal horn neurons (Figure 4F and Supplemental Figure 8 ). These findings indicate that the $\mu$ opioid receptor triggers activation of the dorsal horn mTOR pathway during chronic morphine exposure.

PI3K/Akt mediates $\mu$ opioid receptor-triggered dorsal horn $m$ TOR activation during chronic morphine exposure. Studies of the tyrosine kinase class of receptors ( $G$ protein-coupled receptors) showed that, upon agonist binding, the GTP-bound Ga subunit dissociates from the $G \beta \gamma$ subunit. The $G \beta \gamma$ subunit then activates the $\mathrm{PI} 3 \mathrm{~K} / \mathrm{Akt} / \mathrm{mTOR}$ pathway (17). Given that the $\mu$ opioid receptor is also a G protein-coupled receptor, PI3K and Akt may participate in $\mu$ opioid receptor-dependent activation of $\mathrm{mTOR}$ in dorsal horn neurons. We therefore challenged the cultured dorsal horn neurons with morphine plus $10 \mu \mathrm{M}$ LY294002 (specific PI3K inhibitor) or $5 \mu \mathrm{M}$ Akt inhibitor IV (specific Akt inhibitor). Both inhibitors significantly attenuated morphine-induced 
A
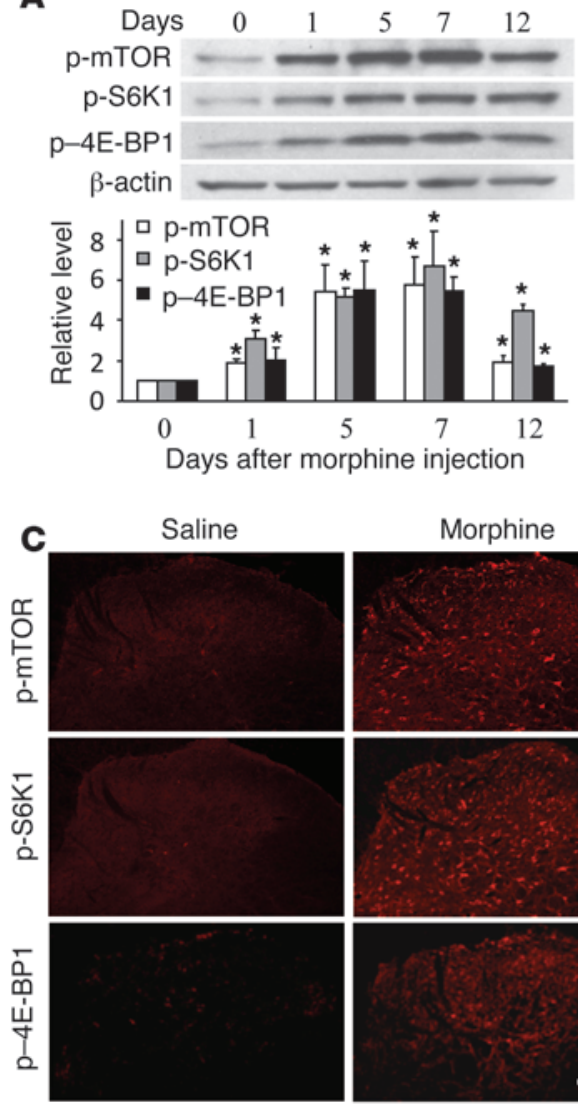

Morphine
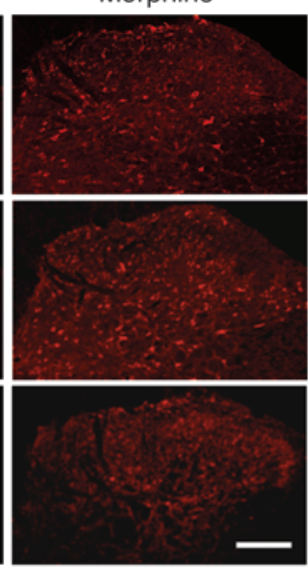

B
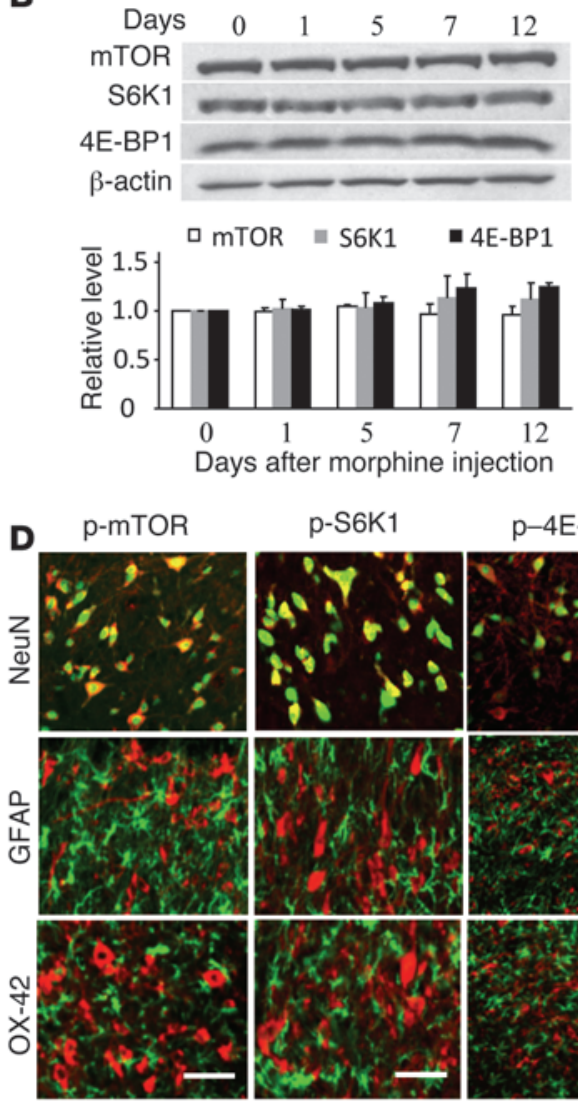

p-S6K1

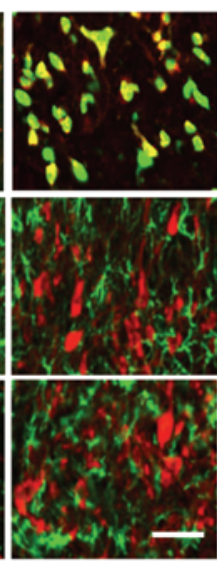

p-4E-BP1

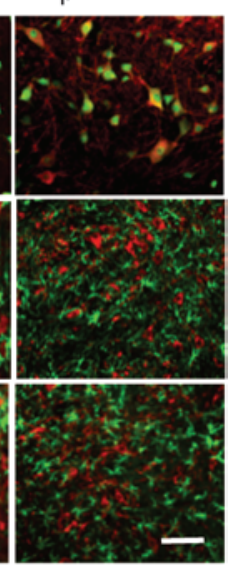

\section{Figure 3}

Repeated intrathecal morphine injections activate the mTOR pathway in dorsal horn neurons. (A and B) Repeated intrathecal morphine injections caused time-dependent increases in p-mTOR, p-S6K1, and p-4E-BP1 (A), but did not change the levels of total mTOR, S6K1, or 4E-BP1 (B), in dorsal horn. Representative Western blots and summary of densitometric analysis (normalized to $\beta$-actin loading control) are shown. ${ }^{\star} P<0.05$ vs. day $0 . n=5$ rats per group. (C) Distribution of neurons labeled by $p$-mTOR, $p$-S6K1, or $p-4 \mathrm{E}-\mathrm{BP} 1$ in dorsal horn 7 days after saline or morphine injection. Scale bar: $100 \mu \mathrm{m}$. (D) Exclusive localization of p-mTOR, p-S6K1, and p-4E-BP1 in dorsal horn neurons on day 7 of twicedaily intrathecal morphine injections. Scale bars: $50 \mu \mathrm{m}$.

increases in p-mTOR and p-S6K1 in dorsal horn neurons (Figure 5, A and B). Both also markedly blocked DAMGO-induced increases in $\mathrm{p}-\mathrm{mTOR}, \mathrm{p}-\mathrm{S} 6 \mathrm{~K} 1$, and $\mathrm{p}-4 \mathrm{E}-\mathrm{BP} 1$ in dorsal horn neurons (Figure 5, C and D). As expected, neither inhibitor alone affected basal phosphorylation levels (Figure 5, C and D). In rats, intrathecal injection of neither $10 \mu \mathrm{g}$ LY294002 nor $10 \mu \mathrm{g} \mathrm{Akt}$ inhibitor IV alone altered basal response to thermal stimulation; however, each blocked the morphine-induced decrease in MPAE and increase in p-mTOR, p-S6K1, and p-4E-BP1 in dorsal horn neurons (Figure 5, E-H). p-Akt was also time-dependently increased in dorsal horn after morphine injection (Supplemental Figure 9). Moreover, single-cell RT-PCR revealed coexpression of $\mu$ opioid receptor mRNA with PI3K $\gamma$, Akt, and mTOR mRNA in individual dorsal horn neurons (Figure 5I). The evidence strongly suggests involvement of PI3K/Akt in $\mu$ opioid receptor-triggered activation of the mTOR pathway in dorsal horn neurons.

$m$ TOR controls dorsal horn protein translation during chronic morphine exposure. We further defined how $\mathrm{mTOR}$ is implicated in morphine tolerance and hyperalgesia. $\mathrm{mTOR}$ activation releases eIF4E from 4E-BP, allows for eIF4E binding to the $\mathrm{m}^{7} \mathrm{GTP}$ cap structure of the mRNA, causes formation of an initiation complex, and initi- ates protein translation (18). Repeated intrathecal morphine injections activated the mTOR pathway, as expected, but also increased translation initiation activity, as demonstrated by increased binding of eIF4A (a component of the initiation complex) to eIF4E and decreased binding of 4E-BP1 to eIF4E (Figure 6, A and B). Repeated intrathecal morphine injections also augmented nascent protein synthesis, as evidenced by increased incorporation of the amino acid analog L-azidohomoalanine (AHA) into newly synthesized proteins in dorsal horn (Figure 6, C and D). These effects were completely abolished by intrathecal coinjection of rapamycin (Figure 6, A-D).

Dorsal horn PKC $\gamma, \mathrm{nNOS}$, and CaMKII $\alpha$ are key players in the mechanisms of morphine tolerance and hyperalgesia, as upregulation of these proteins leads to sensitization of pronociceptive pathways $(19,20)$. Consistent with previous reports $(5,6,9)$, repeated intrathecal morphine injections increased PKC $\gamma$, nNOS, and CaMKII $\alpha$ expression in dorsal horn (Figure 6, E and F). Coinjection of rapamycin significantly attenuated these increases, although it did not alter basal expression of PSD-95 and PKC $\beta$ (Figure 6, E and F). Interestingly, rapamycin coinjection did not affect morphine-induced increases in GFAP and OX-42 expression in dorsal horn (Supplemental Figure 10). Additionally, single-cell 
A
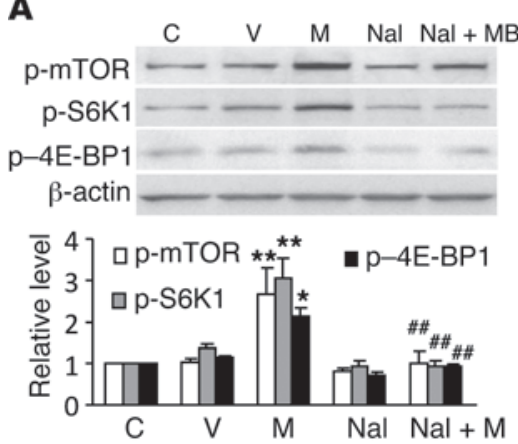

D
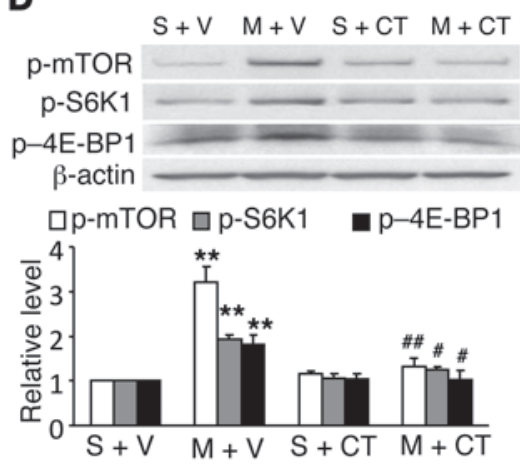

B
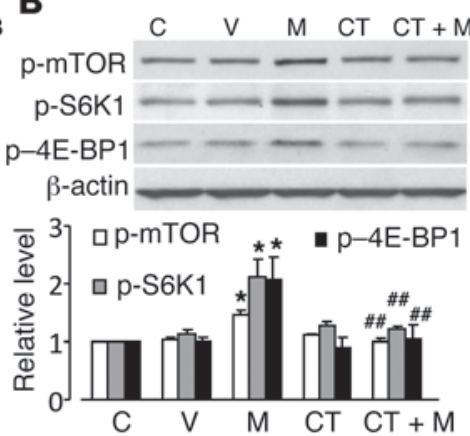

E

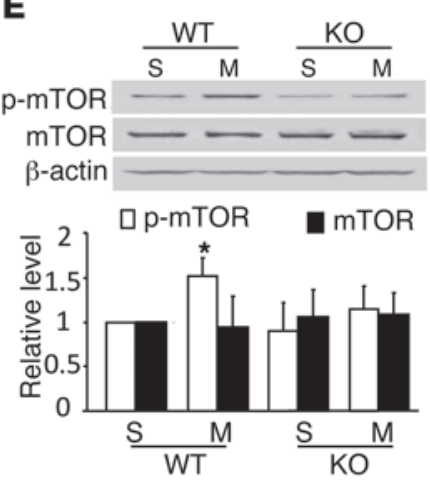

C
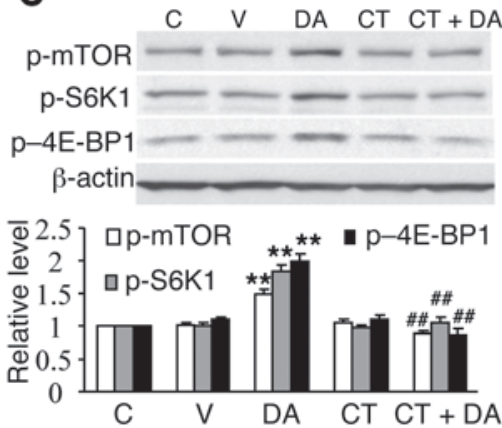

$\mathbf{F}$

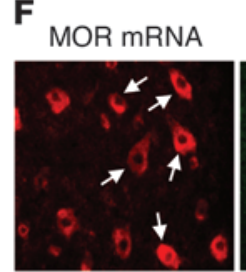

MOR mRNA

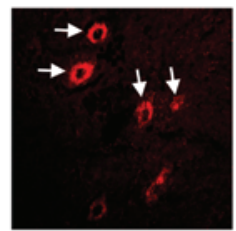

mTOR

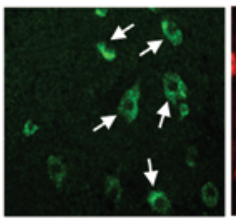

p-mTOR

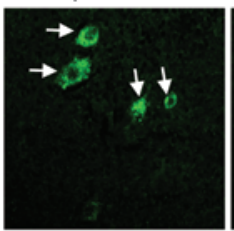

Merged

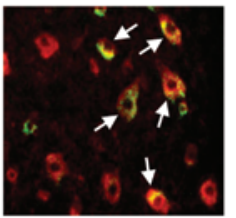

Merged

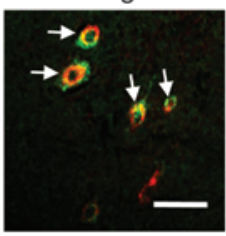

\section{Figure 4}

Morphine-induced activation of the mTOR pathway is $\mu$ opioid receptor dependent in dorsal horn neurons during chronic morphine exposure. (A and B) Naltrexone (Nal, $100 \mu \mathrm{M}$; A) and CTOP (CT, $10 \mu \mathrm{M}$; B) blocked morphine-induced (20 $\mu \mathrm{M})$ increases in p-mTOR, p-S6K1, and p-4E-BP1 in cultured dorsal horn neurons. ${ }^{\star} P<0.05$, ${ }^{\star \star} P<0.01$ vs. control (C); ${ }^{\# \#} P<0.01$ vs. morphine. $n=4-5$ repeats per group. (C) CTOP (10 $\mu \mathrm{M})$ blocked DAMGO-induced (DA, $20 \mu \mathrm{M})$ increases in p-mTOR, p-S6K1, and p-4E-BP1 in cultured dorsal horn neurons. ${ }^{* *} P<0.01 \mathrm{vs}$. control; $\# \#<0.01$ vs. DAMGO. $n=4-5$ repeats per group. (D) Coinjection of CTOP (1 ng) blocked morphine-induced (10 $\mu \mathrm{g})$ increases in $\mathrm{p}$-mTOR, $\mathrm{p}-\mathrm{S} 6 \mathrm{~K} 1$, and $\mathrm{p}-4 \mathrm{E}-\mathrm{BP} 1$ in dorsal horn on day 7 of twice-daily intrathecal morphine injections. ${ }^{\star \star} P<0.01$ vs. saline plus vehicle; ${ }^{\#} P<0.05$, $\# \# P<0.01$ vs. morphine plus vehicle. $n=5$ rats per group. (E) Subcutaneous injection of morphine (20 mg/kg, twice daily for 5 days) increased the level of dorsal horn p-mTOR in wild-type mice, but not in $\mu$ opioid receptor knockout mice. ${ }^{*} P<0.05$ vs. saline-treated wild-type. $n=4$ mice per group. (F) Colocalization (arrows) of $\mu$ opioid receptor (MOR) mRNA with mTOR and p-mTOR in dorsal horn neurons on day 7 of twice-daily intrathecal morphine injections. Scale bar: $50 \mu \mathrm{m}$.

RT-PCR revealed coexpression of $\mu$ opioid receptor and $\mathrm{mTOR}$ mRNA with PKC $\gamma$, nNOS, and CaMKII $\alpha$ mRNA in individual dorsal horn neurons (Figure 6G). Taken together, these findings suggest that activation of the spinal mTOR pathway likely gates translation of many individual proteins in dorsal horn during chronic morphine exposure.

Elevating dorsal horn $m$ TOR activation decreases morphine analgesia and produces byperalgesia. Finally, we investigated whether mimicking morphine-induced dorsal horn mTOR activation alters morphine's analgesic effect and nociceptive behavior thresholds. Tuberous sclerosis complex 1 (TSC1) and TSC2 are negative regulators of $\mathrm{mTOR}$. They form a heterodimeric complex to suppress mTORC1 activity $(21,22)$. Loss of either TSC1 or TSC2 results in robust mTORC1 activation (23). To elevate the activity of spinal mTOR, we knocked down TSC2 with intrathecal TSC2 siRNA. In rats treated with $4 \mu \mathrm{g}$ TSC 2 siRNA, TSC 2 expression was specifically and selectively reduced by $65 \%$ compared with saline-treated controls $(P<0.01$; Figure 7A). TSC2 siRNA did not alter basal levels of total mTOR or S6K1 proteins. In con- trast, p-mTOR, p-S6K1, and nNOS expression increased 2.25-, 2.29-, and 1.53-fold, respectively, in dorsal horn of TSC2 siRNAtreated versus control rats (all $P<0.01$; Figure 7A). More importantly, rats treated with TSC2 siRNA exhibited reduced analgesic effects of morphine. TSC2 siRNA decreased morphine's MPAE by $72 \%$ compared with the control value and produced a substantial rightward shift in the cumulative dose-response curve (Figure 7, B and C). In addition, TSC2 siRNA-treated rats showed marked mechanical and thermal pain hypersensitivities. Left and right hind paw withdrawal thresholds in response to mechanical stimuli were reduced by $80.2 \%$ and $81.6 \%$, respectively, compared with those of the control group (both $P<0.01$; Figure 7D). Likewise, left hind paw withdrawal latency was reduced by $38.7 \%$ in response to thermal stimulation, and right hind paw withdrawal latency by $25.2 \%$ (both $P<0.05$; Figure 7E). Scrambled TSC2 siRNA (4 $\mu \mathrm{g})$ did not significantly alter basal levels of any of the tested proteins, morphine analgesia, or basal paw withdrawal responses to mechanical or thermal stimuli (Figure 7, A-E). 

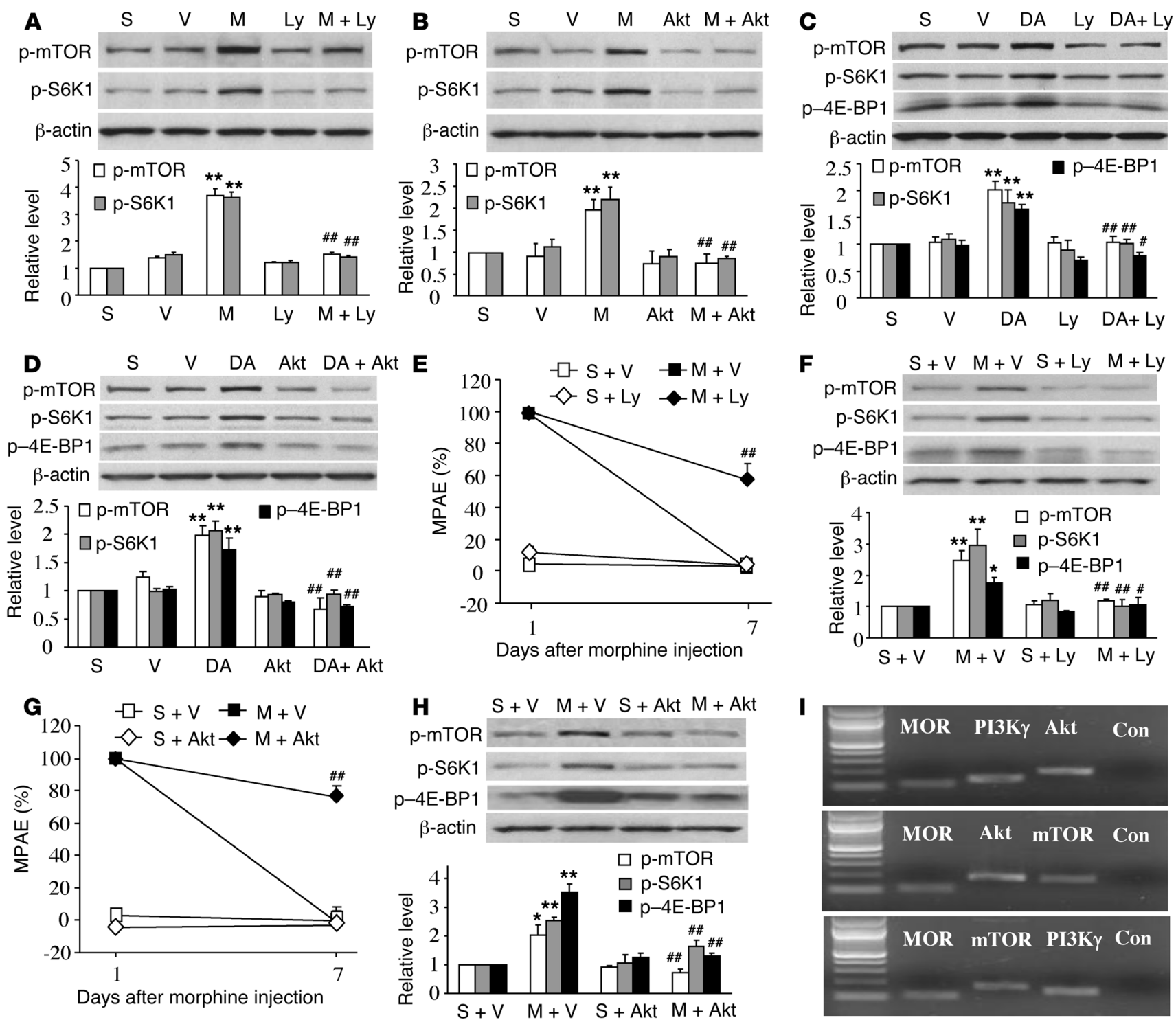

Figure 5

PI3K/Akt mediates $\mu$ opioid receptor-dependent activation of the mTOR pathway in dorsal horn neurons during chronic morphine exposure. (A and B) Coadministration of LY294002 (Ly, $10 \mu \mathrm{M}$; A) or Akt inhibitor IV (Akt, $5 \mu \mathrm{M}$; B) blocked morphine-induced (20 $\mu \mathrm{M})$ increases in p-mTOR and $p$-S6K1 in cultured dorsal horn neurons. ${ }^{* \star} P<0.01$ vs. saline; $\# P<0.01$ vs. morphine. $n=4$ repeats per group. (C and D) Coadministration of LY294002 (10 $\mu \mathrm{M}$; C) or Akt inhibitor IV (5 $\mu \mathrm{M}$; D) blocked DAMGO-induced (20 $\mu \mathrm{M})$ increases in p-mTOR, p-S6K1, and p-4E-BP1 in cultured dorsal horn neurons. ${ }^{* \star} P<0.01$ vs. saline; $\# P<0.05$, $\# P<0.01$ vs. DAMGO. $n=4$ repeats per group. (E-H) Coinjection of LY294002 (10 $\mu$; $\mathbf{E}$ and $\mathbf{F})$ or Akt inhibitor IV (10 $\mu \mathrm{g} ; \mathbf{G}$ and $\mathbf{H})$ blocked morphine-induced (10 $\mu \mathrm{g})$ decrease in MPAE (E and $\mathbf{G})$ and increases in p-mTOR, p-S6K1, and p-4E-BP1 in dorsal horn ( $\mathbf{F}$ and $\mathbf{H})$ on day 7 of twice-daily intrathecal morphine injections. ${ }^{*} P<0.05$, ${ }^{* \star} P<0.01$ vs. saline plus vehicle; ${ }^{\#} P<0.01$ vs. morphine plus vehicle. $n=5$ rats per group. (I) Coexpression of $\mu$ opioid receptor mRNA with PI3K $\gamma$, Akt, and mTOR mRNA in individual dorsal horn neurons. Con, control. $n=3$ rats.

\section{Discussion}

In the present study, we provided what we believe to be the first evidence that $\mathrm{mTOR}$ and its downstream effectors are activated through a $\mu$ opioid receptor-triggered PI3K/Akt pathway in dorsal horn neurons during chronic morphine exposure. Our observations suggest that spinal mTOR activation contributes to the development and maintenance of chronic morphine tolerance and morphine-induced hyperalgesia via increases in dorsal horn protein translation. Spinal mTOR is likely a novel target for prevent- ing and/or treating chronic morphine tolerance and morphineinduced hyperalgesia.

The mechanisms that underlie morphine tolerance and hyperalgesia are not fully understood, but are generally considered to result from adaptive changes within the peripheral and central nervous systems. Adaptive modifications in $\mu$ opioid receptor-mediated cellular responsiveness, particularly in desensitization and downregulation of the $\mu$ opioid receptor, may be at the origin of morphine tolerance $(3,24)$, whereas adaptive 
A

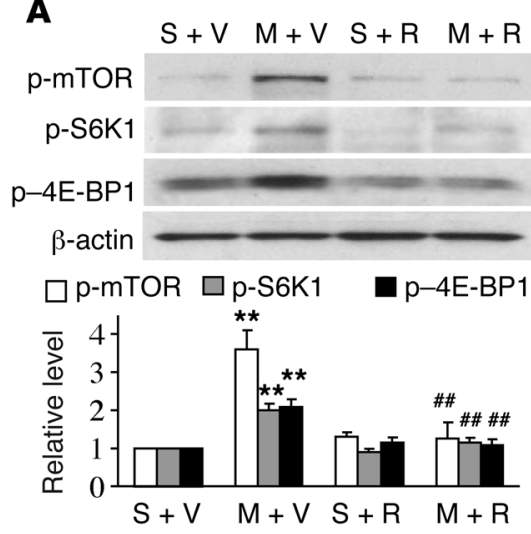

B
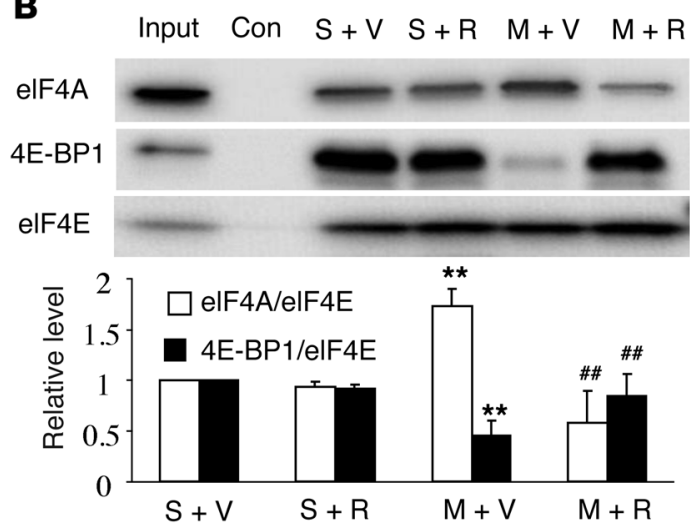

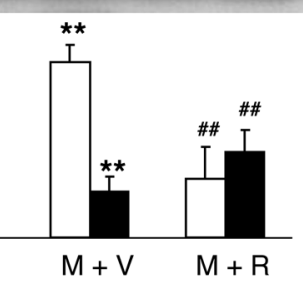

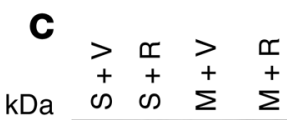

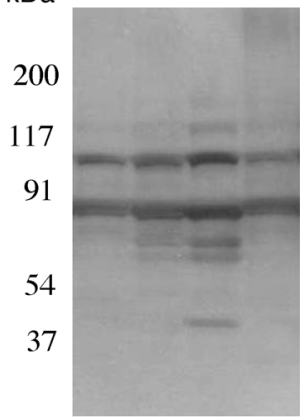

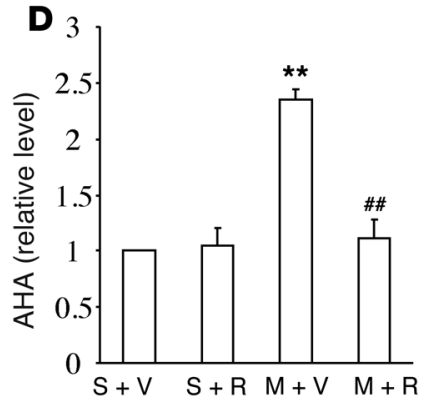

E nNOS PKC $\gamma$ PKC $\beta$ PSD-95 $\beta$-actin
$S+V$

\section{st}

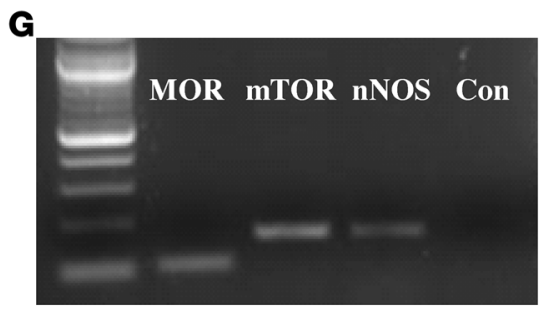

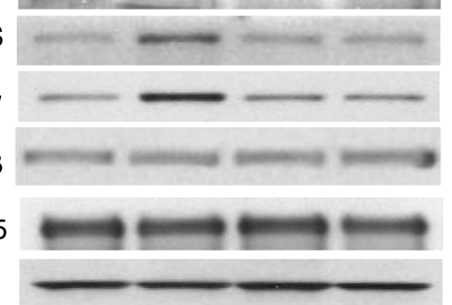

$\mathbf{F}$
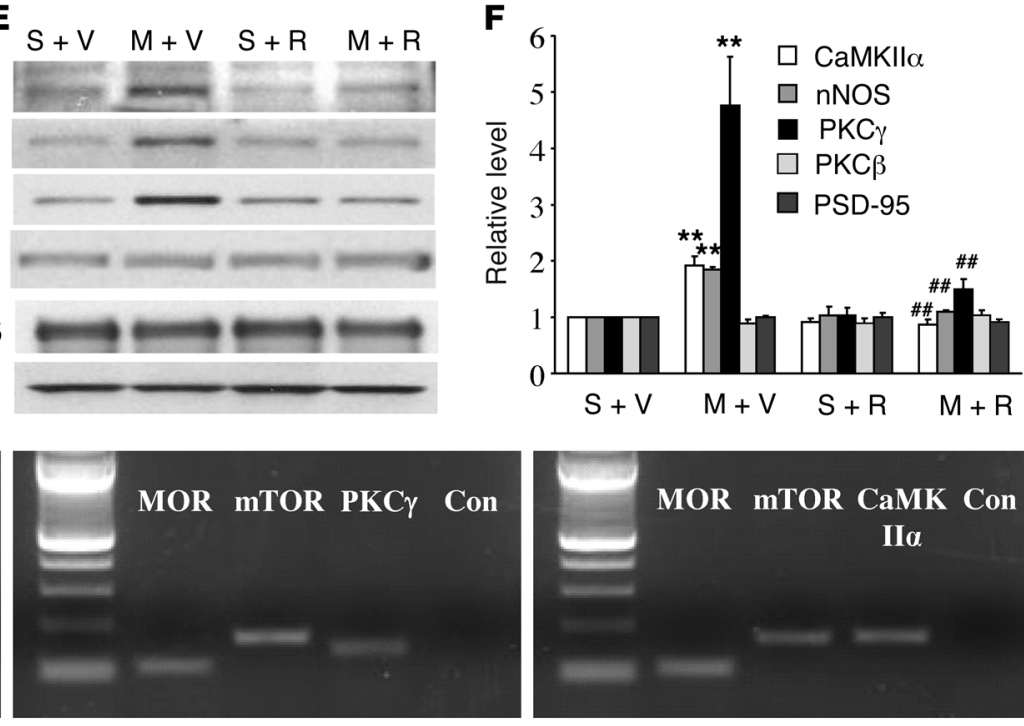

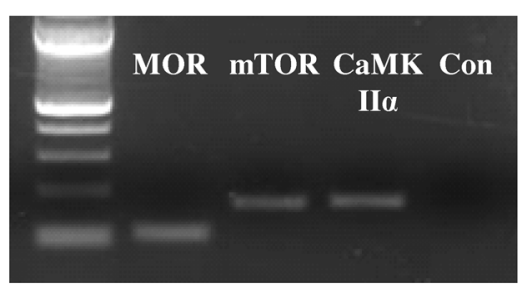

\section{Figure 6}

Twice-daily intrathecal morphine injections enhance mTOR-dependent protein translation in dorsal horn on day 7. (A) Coinjection of rapamycin $(10 \mu \mathrm{g})$ blocked morphine-induced $(10 \mu \mathrm{g})$ increases in p-mTOR, p-S6K1, and p-4E-BP1 in dorsal horn. (B) Coinjection of rapamycin blocked the morphine-induced increase in association between elF4A and elF4E and reversed the morphine-induced decrease in association between 4E-BP1 and elF4E in dorsal horn. (C and D) Coinjection of rapamycin blocked the morphine-induced increase in AHA incorporation into newly synthesized proteins in dorsal horn. (E and F) Coinjection of rapamycin blocked morphine-induced increases in CaMKIl $\alpha$, nNOS, and PKC $\gamma$, but did not affect basal levels of PKC $\beta$ or PSD-95, in dorsal horn. $(\mathbf{A}-\mathbf{F}){ }^{* *} P<0.01$ vs. saline plus vehicle; \#\# $P<0.01$ vs. morphine plus vehicle. $n=4$ rats per group. (G) Coexpression of $\mu$ opioid receptor and mTOR mRNA with nNOS, PKC $\gamma$, or CaMKIl $\alpha$ mRNA in individual dorsal horn neurons. $n=3$ rats.

changes in neuronal circuits - such as activation of anti-opioid systems - reduce sensory thresholds, resulting in hypersensitivity to mechanical and thermal noxious stimuli (8). Morphineinduced pain hypersensitivity may further diminish the net analgesic effect of morphine and augment morphine tolerance. Adaptive responses often result from changes in protein translation $(17,25)$. Indeed, we showed that repeated intrathecal injections of morphine increased translational initiation activity and nascent protein synthesis in dorsal horn. Consistent with previous reports $(5,6,9)$, dorsal horn PKC $\gamma, \mathrm{nNOS}$, and CaMKII $\alpha$ were upregulated after intrathecal morphine injections. All of these translational changes were blocked by spinal mTOR inhibition. These findings suggest that mTOR governs dorsal horn neuronal adaptation during chronic morphine exposure and contributes to the mechanisms of chronic morphine tolerance and hyperalgesia. This conclusion was further supported by our findings that spi- nal mTOR inhibition attenuated development and maintenance of morphine tolerance and hyperalgesia and that mTOR and its downstream effectors were significantly activated in dorsal horn neurons upon morphine stimulation. Although mTOR activation in vivo did not coincide temporally with induction of morphine tolerance and hyperalgesia, this inconsistency reflects the fact that protein translation and adaptive changes take some time to occur after mTOR becomes activated. Moreover, mimicking morphine-induced dorsal horn mTOR activation by knocking down the mTOR-negative regulator TSC2 reduced morphine's analgesic effect, caused mechanical and thermal pain hypersensitivity, and upregulated dorsal horn nNOS. This evidence strongly supports a key role of spinal mTOR in chronic morphine tolerance and morphine-induced hyperalgesia.

One important observation that emerged from our study is that morphine activates mTOR through a $\mu$ opioid receptor-trig- 

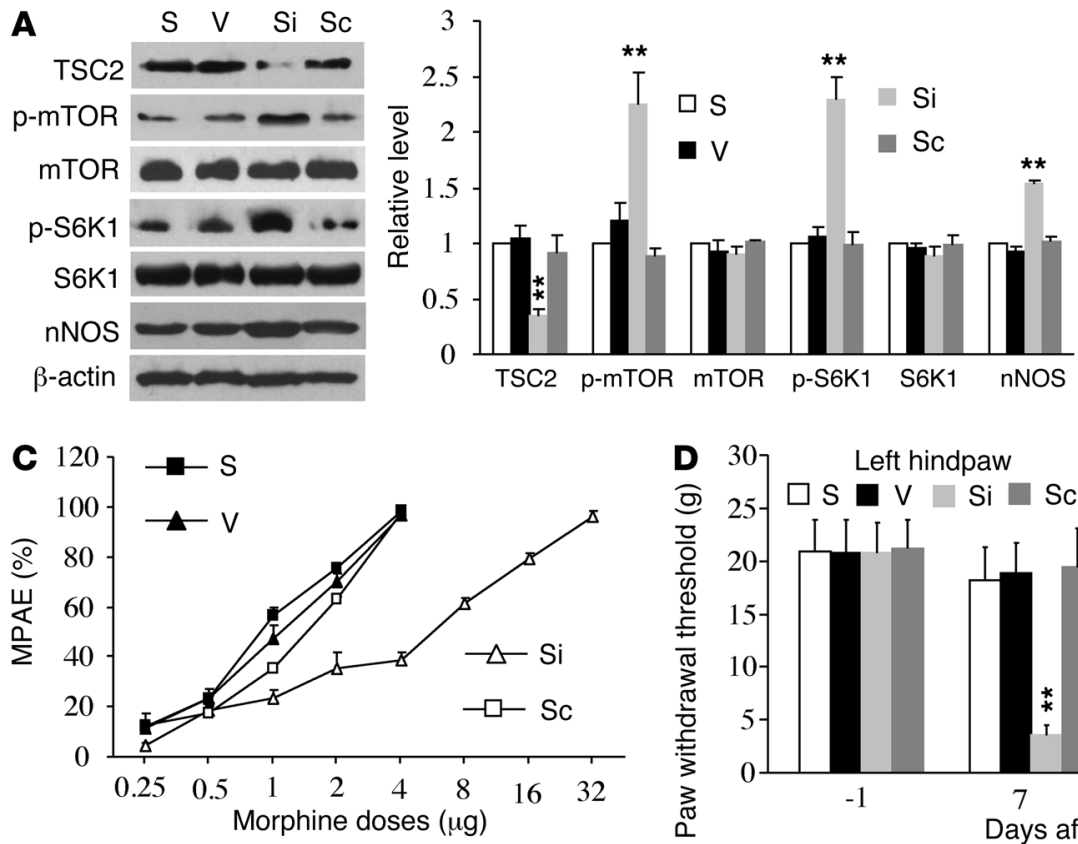
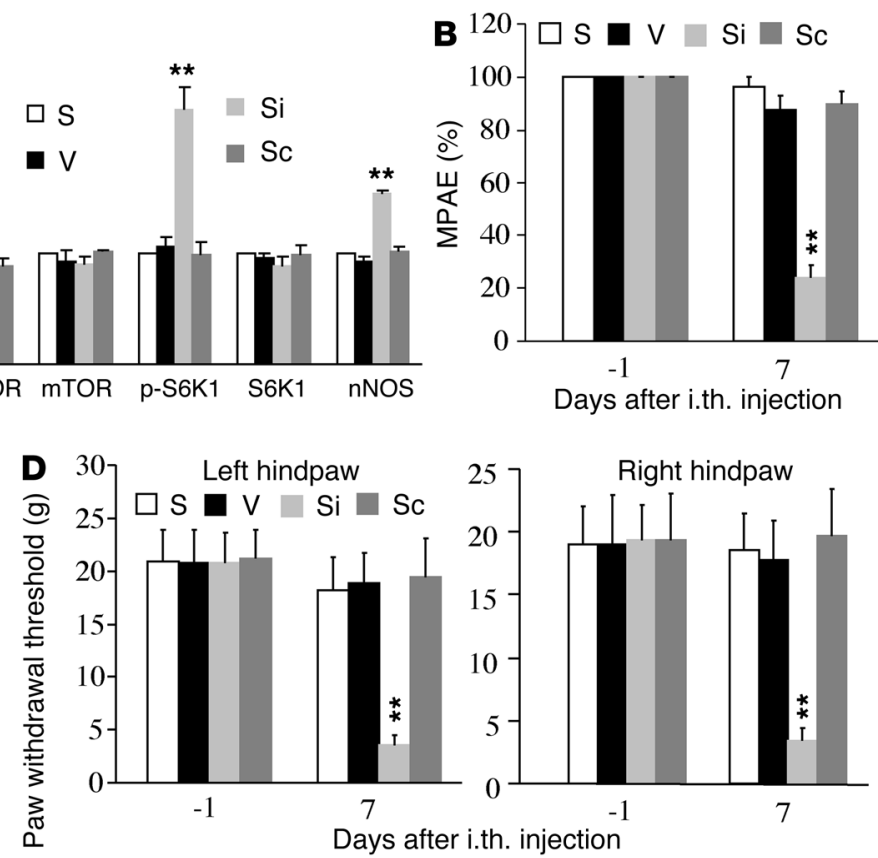

Days after i.th. injection

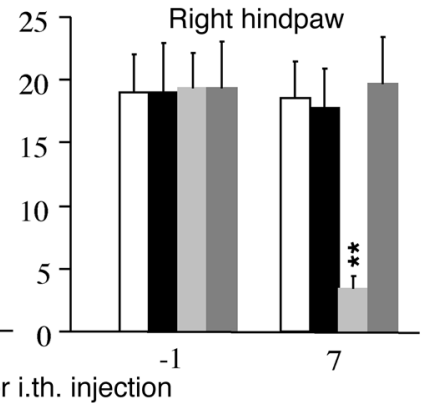

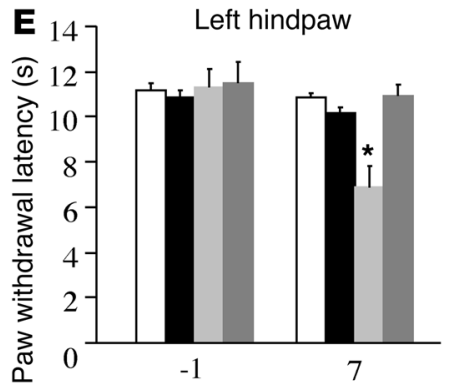

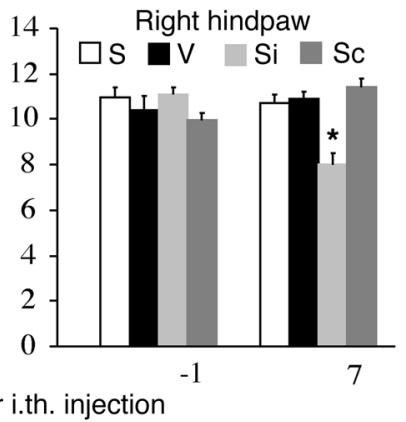

Figure 7

Elevating mTOR activity by knocking down TSC2 reduces morphine analgesia and induces pain hypersensitivity. Saline, vehicle, TSC2 siRNA, or scrambled TSC2 siRNA was injected intrathecally once daily for 3 days. Protein expression and MPAE were measured on day 7. (A) TSC2 siRNA $(4 \mu \mathrm{g})$, but not scrambled TSC2 siRNA $(4 \mu \mathrm{g})$, reduced TSC2 expression, increased p-mTOR, p-S6K1, and nNOS levels, and had no effect on total mTOR or S6K1 protein expression. (B and C) TSC2 siRNA, but not scrambled TSC2 siRNA, reduced morphine MPAE (B) and produced a significant rightward shift in the cumulative dose-response curve of morphine (C). (D and E) TSC2 siRNA, but not scrambled TSC2 siRNA, reduced left and right hindpaw withdrawal thresholds in response to mechanical stimuli (D) and withdrawal latencies in response to thermal stimuli (E). ${ }^{\star} P<0.05,{ }^{* \star} P<0.01$ vs. saline. $n=4(\mathrm{~A})$ or $5(\mathrm{~B}-\mathrm{E})$ rats per group.

gered PI3K/Akt pathway in dorsal horn neurons. Pharmacologic inhibition or genetic knockout of dorsal horn $\mu$ opioid receptor blocked morphine-stimulated increases in p-mTOR, p-S6K1, and $\mathrm{p}-4 \mathrm{E}-\mathrm{BP} 1$ in dorsal horn neurons. Activation of the $\mu$ opioid receptor increased phosphorylation of these 3 proteins. Neither $\delta$ nor $\kappa$ opioid receptor antagonists affected morphine-stimulated phosphorylation increases, but the role of $\delta$ and $\kappa$ opioid receptors in dorsal horn mTOR activation still cannot be ruled out. Whether activation of dorsal horn $\delta$ or $\kappa$ opioid receptors activates mTOR remains to be determined. Inhibition of spinal PI3K/Akt not only attenuated morphine tolerance development, but also lessened morphine-induced increases in p-mTOR, p-S6K1, and p-4E-BP1 in dorsal horn. Additionally, dorsal horn Akt was time-dependently activated after repeated intrathecal morphine injections. Given that $\mu$ opioid receptor, PI3K $\gamma$, Akt, and mTOR coexpressed in dorsal horn neurons, it is very likely that PI3K/Akt directly medi- ates $\mu$ opioid receptor-triggered activation of dorsal horn mTOR and its downstream effectors during chronic morphine exposure. Our observations are also supported by previous in vitro studies in which DAMGO-induced activation of Akt, S6K1, and 4E-BP1 were blocked by both PI3K inhibitors and rapamycin in a $\mu$ opioid receptor-transfected cell line (26). It should be noted that the mTOR pathway can also be activated by the glutamate receptor/ ERK/MAPK pathway in central neurons (27-30). We recently reported that $\mathrm{mTOR}$ colocalizes with the NMDA receptor subunit NR1 in dorsal horn neurons and that cancer pain-triggered dorsal horn mTOR activation is blocked by NMDA receptor antagonists (31). It is well documented that spinal glutamate receptors (including NMDA receptors) and the ERK/MAPK pathway are involved in morphine-induced tolerance $(32,33)$. Thus, the role of the glutamate receptor/ERK/MAPK pathway in mTOR activation during chronic morphine exposure cannot be ruled out. 
As in the dorsal horn, prolonged morphine exposure also causes adaptive changes in protein translation in DRG. For example, chronic morphine exposure caused TRPV1, ERK, c-Jun, and p38MAPK to increase in the DRG (14). The adaptation in the DRG contributes to tolerance and hyperalgesia through modulation of neurotransmitter release in primary afferents $(14,34,35)$. mTOR-gating protein translation does not appear to participate in the adaptation in the DRG, as we did not see a significant increase in DRG p-mTOR during the observation period. However, we cannot completely rule out the possibility that Western blotting may not be sensitive enough to detect small increases in DRG p-mTOR. Another possibility is that the dose of morphine we used may not be adequate to stimulate a measurable increase in $\mathrm{p}$-mTOR in DRG. Fragile $\mathrm{X}$ mental retardation protein and 2 transcription factors, NF- $\mathrm{KB}$ and $\mathrm{FOXO}$, are also involved in protein translation $(36,37)$. It is possible that these proteins, rather than $\mathrm{mTOR}$, are involved in DRG adaptive changes under chronic morphine exposure conditions.

Numerous investigators have studied the role of spinal glia in chronic morphine tolerance and hyperalgesia. Chronic exposure to morphine leads to activation of astrocytes and microglia, increases in expression of various signaling receptors in their bodies, and release of proinflammatory cytokines in dorsal horn $(7,38,39)$. Administration of glial metabolic inhibitors, receptor antagonists, or cytokine inhibitors attenuates the development of analgesic tolerance and hyperalgesia in response to morphine $(7,38-41)$. It is evident that, as in dorsal horn neurons, morphine-induced adaptive changes in dorsal horn glial cells are involved in the development of morphine tolerance and hyperalgesia. Interestingly, we found that spinal mTOR inhibition did not affect morphine-induced hypertrophy of astrocytes and microglia or the increase in GFAP expression in dorsal horn. Moreover, we and others $(11,31,42-46)$ have shown that mTOR, $\mathrm{p}-\mathrm{mTOR}, \mathrm{PI} 3 \mathrm{~K} \gamma, \mathrm{Akt}$, and $\mathrm{p}$-Akt are undetectable in spinal cord glial cells of naive rats, in rats given repeated morphine injections, and in rats with inflammation or nerve injury. Additionally, $\mu$ opioid receptor was not expressed in spinal cord astrocytes or microglia from naive adult rats or adult rats administered repeated morphine injections (47), although $\mu$ opioid receptor was previously reported to be expressed in spinal microglia in in vitro culture (48). These findings suggest that spinal glial cells are indirectly activated by morphine and that $\mu$ opioid receptortriggered mTOR activation does not participate in protein translation changes in spinal cord glial cells during chronic morphine exposure. Although the mechanisms by which morphine causes dorsal horn glial adaptive changes remain unclear, we cannot exclude the role of spinal glia in chronic morphine tolerance and hyperalgesia, because spinal mTOR inhibition attenuated, but did not completely abolish, the development and maintenance of chronic morphine tolerance and hyperalgesia.

It is generally believed that opioid tolerance and hyperalgesia share common cellular mechanisms, as the same manipulation can block both phenomena in preclinical and clinical studies $(14,20,49-52)$. Our finding that spinal mTOR inhibition blocks both morphine tolerance and hyperalgesia strongly favors this commonly held view. Clinical observations that opioid tolerance and hyperalgesia have distinct features suggest that at least some of the cellular mechanisms underlying these 2 phenomena are different. Indeed, a recent study showed that microglia-mediated disruption of dorsal horn neuronal $\mathrm{Cl}^{-}$homeostasis was required for morphine hyperalgesia, but not for morphine tolerance (53). Establishing an approach that blocks only morphine hyperalgesia may provide an opportunity to enhance the utility of morphine to overcome morphine tolerance. However, increasing doses of morphine may also produce other severe side effects, such as oversedation, respiratory depression, and constipation. Accordingly, as an adjuvant therapy, targeting shared mechanisms may be a more optimal strategy for preventing and/or treating morphine tolerance and hyperalgesia.

In summary, our findings revealed a new $\mu$ opioid receptortriggered intracellular pathway in dorsal horn neurons that underlies mechanisms of morphine tolerance and hyperalgesia. Under normal conditions, this pathway is inactive. During chronic morphine exposure, binding of morphine to the $\mu$ opioid receptor activates PI3K/Akt, which directly phosphorylates TSC2 and releases the suppression of TSC1/TSC2 on dorsal horn mTORC1. mTOR activation activates $\mathrm{S} 6 \mathrm{~K}$ and $4 \mathrm{E}-\mathrm{BP}$, resulting in the initiation of mRNA translation and adaptive changes in protein translations in dorsal horn. Therefore, $\mathrm{mTOR}$ is a key regulator of dorsal horn adaptation during chronic morphine exposure. mTOR inhibitors have been approved by the FDA as immunosuppressive drugs (15) and have been used in a phase II/III clinical trial for cancer treatment (54). Spinal mTOR inhibition also produces an antinociceptive effect in neuropathic and cancer pain without affecting acute pain or producing significant immunosuppression or other side effects $(31,55)$. Our recent study showed that blocking spinal mTOR attenuated analgesic tolerance and hyperalgesia induced by continuously intrathecal infusion of morphine in rats with neuropathic pain (data not shown). Thus, intrathecal use of mTOR inhibitors clinically will likely have triple benefits: anticancer, antinociception/anti-cancer pain, and antitolerance/hyperalgesia.

\section{Methods}

Animal preparations. Intrathecal polyethylene-10 (PE-10) catheters were implanted into male Sprague-Dawley rats (200-250 g). Each catheter was inserted into the subarachnoid space rostrally at the lumbar enlargement through a hole between $L_{5}$ and $S_{1}$. Male $\mu$ opioid receptor knockout mice and wild-type littermates were obtained by breeding $\mu$ opioid receptor heterozygous mice.

Tolerance models and behavioral analysis. Rats were injected intrathecally with saline $(10 \mu \mathrm{l})$ or morphine $(10 \mu \mathrm{g} / 10 \mu \mathrm{l})$ twice daily for 6 consecutive days with or without coinjection of vehicle or antagonists/inhibitors. Mice were injected with saline or morphine $(10 \mathrm{mg} / \mathrm{kg})$ subcutaneously every 12 hours for 6 consecutive days. Cumulative dose-response curves as described previously (56) were determined on day 7 after induction of chronic morphine tolerance or on day 7 after TSC2 siRNA injection. Rats were injected intrathecally with a very low morphine dose $(0.25 \mu \mathrm{g})$, and analgesia was assessed 30 minutes later by the tail-flick assay. Rats that were not analgesic at the first dose then received a second dose (cumulative dosing increase by 2 -fold) and were tested 30 minutes afterward. This procedure was repeated until the rats failed to move their tail within the cutoff time or no additional increase in tail-flick latency was noted from one dose to the next.

We habituated animals in the testing environments for 2 days and carried out behavioral testing in a blinded manner. 4 behavioral tests (tail flick, mechanical, thermal, and locomotor) were used. Tail flick latency to noxious heat was measured 1 day before drug injection and at 0.5 hour after intrathecal morphine or saline injection on mornings $1,3,5,7,9$, or 12. Paw withdrawal thresholds and latencies in response to mechanical and thermal stimuli, respectively, were measured 1 day before drug injection and 
2 hours before the tail-flick test on day 7 or 12 as described previously (57). Tests of locomotor function, including placing, grasping, and righting reflexes, were performed before and after drug injection according to previously described protocols (57).

siRNA design and transfection. An mTOR siRNA duplex corresponding to bases 2162-2182 from the open reading frame of rat mTOR mRNA 5'-UGAACCCUGCCUUUGUCAUGC-3' (rapamycin binding site; GenBank accession number NM_019906) was designed. A mismatch siRNA with scrambled sequence and no known homology to a rat gene (scrambled siRNA, 5'-UACUUUUCGGUCCCGACGUCATT-3', 5'-UGACGUCGGGACCGAAAAGUATT-3') was used as a control. siRNAs were synthesized by Cell Signaling Technology Inc. TSC2 siRNA (catalog no. 6548) and its control scrambled siRNA (catalog no. 6568) were purchased from Cell Signaling Technology Inc. We used TurboFect in vivo transfection reagent (Thermo Scientific Inc.) as a delivery vehicle for siRNA to prevent degradation and enhance cell membrane penetration of siRNA. Rats were injected intrathecally with siRNA or vehicle once daily for 3 days. On day 7 , rats were administered intrathecal injections of saline or morphine as described above.

$5^{\prime}$ mRNA cap complex analysis. Extracted protein was incubated with 7-methyl GTP sepharose 4B beads (GE Healthcare Life Science) in the presence of $100 \mu \mathrm{M}$ GTP overnight at $4^{\circ} \mathrm{C}$. Unconjugated sepharose $4 \mathrm{~B}$ beads were used as negative controls. The beads were then pelleted and washed 3 to 4 times with lysis buffer. After centrifugation, the pellet was suspended in lysis buffer. eIF4E, eIF4A, and 4E-BP1 bound to the precipitated beads were analyzed by Western blotting.

Nascent protein synthesis assay. Transverse slices of the $\mathrm{L}_{4 / 5}$ dorsal horn were incubated in DMEM/F12 supplemented with $50 \mu \mathrm{M}$ AHA (Invitrogen). After 4 hours of incubation at $37^{\circ} \mathrm{C}$, protein was extracted from the dorsal horn by homogenization. We labeled AHA-incorporating proteins with biotin using the Click-iT Biotin Protein Analysis Detection Kit (Invitrogen). The samples were analyzed by Western blotting.

Single-cell RT-PCR. We first dissociated dorsal horn neurons from adult rat spinal cord. 4 hours after plating, the neurons were randomly collected under an inverted microscope fit with a micromanipulator and microinjector. A single living neuron was selected with a glass micropipette, without contamination by other neurons, and placed in a PCR tube with 5 to $10 \mu \mathrm{l}$ of cell lysis buffer (Signosis) as described (57). After centrifugation, the supernatant was collected and divided into 3 PCR tubes for 3 targeting genes. RT-PCR was carried out as described previously
(57). Briefly, using the Omniscript RT kit (Qiagen) with strand-specific primers, we reverse transcribed single-stranded cDNA from RNA $(1 \mu \mathrm{g})$. RT and PCR primers were determined from the UCSC genome database (Supplemental Table 3$)$. Template $(1 \mu \mathrm{l})$ was amplified by PCR with TaKaRa Taq DNA polymerase (Clontech Laboratories, Inc.) in $20 \mu \mathrm{l}$ total reaction volume containing $0.5 \mu \mathrm{M}$ of each specific PCR primer. PCR amplification consisted of 30 seconds at $94^{\circ} \mathrm{C}, 20$ seconds at $56^{\circ} \mathrm{C}$, and 20 seconds at $72^{\circ} \mathrm{C}$ for 35 cycles. After amplification, PCR products were separated on a $2.0 \%$ agarose gel containing $0.025 \%$ ethidium bromide; bands were visualized under UV illumination and photographed with the BioDoc-It imaging system (Ultra-Violet Products Ltd). Products were extracted, purified, and verified by automatic DNA sequencing.

In situ hybridization histochemistry (ISHH). See Supplemental Methods for details, including primers and probes used.

Western blotting and immunohistochemistry. See Supplemental Methods for details, including antibodies used.

Statistics. All results are given as mean \pm SEM. Data were statistically analyzed with 1- or 2-way ANOVA. When ANOVA showed significant difference, pairwise comparisons between means was tested by the post-hoc Tukey method. A $P$ value less than 0.05 was considered significant.

Study approval. All procedures used were approved by the Animal Care and Use Committees of Johns Hopkins University and Rutgers, The State University of New Jersey. These investigations conformed to the NIH Guide for the Care and Use of Laboratory Animals.

\section{Acknowledgments}

This work was supported by NIH grants (NS072206, NS026363, DA033390, and HL117684), the Rita Allen Foundation, and the National Natural Science Foundation of China (31171070). The authors thank Claire F. Levine for editorial assistance.

Received for publication April 1, 2013, and accepted in revised form October 24, 2013.

Address correspondence to: Yuan-Xiang Tao, Department of Anesthesiology, New Jersey Medical School, Rutgers, The State University of New Jersey, 185 S. Orange Ave., MSB, F-548, Newark, New Jersey 07103, USA. Phone: 973.972.9812; Fax: 973.972.1644; E-mail: yuanxiang.tao@njms.rutgers.edu.
1. Renfrey S, Downton C, Featherstone J. The painful reality. Nat Rev Drug Discov. 2003;2(3):175-176.

2. Bekhit MH. Opioid-induced hyperalgesia and tolerance. Am J Ther. 2010;17(5):498-510.

3. Ueda $H$, Ueda M. Mechanisms underlying morphine analgesic tolerance and dependence. Front Biosci (Landmark Ed). 2009;14:5260-5272.

4. Szabo I, et al. Heterologous desensitization of opioid receptors by chemokines inhibits chemotaxis and enhances the perception of pain. Proc Natl Acad Sci US A. 2002;99(16):10276-10281.

5. Granados-Soto V, Kalcheva I, Hua X, Newton A Yaksh TL. Spinal PKC activity and expression: role in tolerance produced by continuous spinal morphine infusion. Pain. 2000;85(3):395-404.

6. Liang D, Li X, Clark JD. Increased expression of $\mathrm{Ca} 2+$ calmodulin-dependent protein kinase II alpha during chronic morphine exposure. Neuroscience. 2004;123(3):769-775.

7. Watkins LR, Hutchinson MR, Milligan ED, Maier SF. "Listening" and "talking" to neurons: implications of immune activation for pain control and increasing the efficacy of opioids. Brain Res Rev. 2007; 56(1):148-169.

8. Ossipov MH, Lai J, King T, Vanderah TW, Porreca F. Underlying mechanisms of pronociceptive consequences of prolonged morphine exposure. Biopolymers. 2005;80(2-3):319-324.

9. Yu L, et al. N(omega)-nitro-L-arginine methyl ester inhibits the up-regulated expression of neuronal nitric oxide synthase/NMDA receptor in the morphine analgesia tolerance rats. Sheng Li Xue Bao. 2006; 58(6):593-598.

10. Gingras AC, Raught B, Sonenberg N. Regulation of translation initiation by FRAP/mTOR. Genes Dev. 2001;15(7):807-826.

11. Xu JT, Zhao X, Yaster M, Tao YX. Expression and distribution of mTOR, p70S6K, 4E-BP1, and their phosphorylated counterparts in rat dorsal root ganglion and spinal cord dorsal horn. Brain Res. 2010; 1336:46-57.

12. Advokat C. Tolerance to the antinociceptive effect of morphine in spinally transected rats. Behav Neurosci. 1989;103(5):1091-1098.

13. Zheng XF, Florentino D, Chen J, Crabtree GR, Schreiber SL. TOR kinase domains are required for two distinct functions, only one of which is inhibited by rapamycin. Cell. 1995;82(1):121-130.

14. Chen Y, Geis C, Sommer C. Activation of TRPV1 contributes to morphine tolerance: involvement of the mitogen-activated protein kinase signaling pathway. J Neurosci. 2008;28(22):5836-5845.
15. Dean PG, et al. Kidney transplant histology after one year of continuous therapy with sirolimus compared with tacrolimus. Transplantation. 2008; 85(8):1212-1215.

16. Trescot AM, Datta S, Lee M, Hansen H. Opioid pharmacology. Pain Physician. 2008; 11(2 suppl):S133-S153.

17. Costa-Mattioli M, Sossin WS, Klann E, Sonenberg N. Translational control of long-lasting synaptic plasticity and memory. Neuron. 2009;61(1):10-26.

18. Proud CG. Signalling to translation: how signal transduction pathways control the protein synthetic machinery. Biochem J. 2007;403(2):217-234.

19. Garzon J, Rodriguez-Munoz M, Sanchez-Blazquez P. Do pharmacological approaches that prevent opioid tolerance target different elements in the same regulatory machinery? Curr Drug Abuse Rev. 2008; 1(2):222-238

20. Lee M, Silverman SM, Hansen H, Patel VB, Manchikanti L. A comprehensive review of opioid-induced hyperalgesia. Pain Physician. 2011; 14(2):145-161.

21. Inoki K, Li Y, Zhu T, Wu J, Guan KL. TSC2 is phosphorylated and inhibited by Akt and suppresses mTOR signalling. Nat Cell Biol. 2002;4(9):648-657.

22. Manning BD, Tee AR, Logsdon MN, Blenis J, 
Cantley LC. Identification of the tuberous sclerosis complex-2 tumor suppressor gene product tuberin as a target of the phosphoinositide 3-kinase/akt pathway. Mol Cell. 2002;10(1):151-162.

23. Fingar DC, Blenis J. Target of rapamycin (TOR): an integrator of nutrient and growth factor signals and coordinator of cell growth and cell cycle progression. Oncogene. 2004;23(18):3151-3171.

24. Taylor DA, Fleming WW. Unifying perspectives of the mechanisms underlying the development of tolerance and physical dependence to opioids. J Pharmacol Exp Ther. 2001;297(1):11-18.

25. Richter JD, Klann E. Making synaptic plasticity and memory last: mechanisms of translational regulation. Genes Dev. 2009;23(1):1-11.

26. Polakiewicz RD, Schieferl SM, Gingras AC, Sonenberg N, Comb MJ. mu-Opioid receptor activates signaling pathways implicated in cell survival and translational control. J Biol Chem. 1998; 273(36):23534-23541.

27. Hou L, Klann E. Activation of the phosphoinositide 3-kinase-Akt-mammalian target of rapamycin signaling pathway is required for metabotropic glutamate receptor-dependent long-term depression. J Neurosci. 2004;24(28):6352-6361.

28. Lenz G, Avruch J. Glutamatergic regulation of the p70S6 kinase in primary mouse neurons. J Biol Chem. 2005;280(46):38121-38124.

29. Ma L, Chen Z, Erdjument-Bromage H, Tempst P, Pandolfi PP. Phosphorylation and functional inactivation of TSC2 by Erk implications for tuberous sclerosis and cancer pathogenesis. Cell. 2005; 121(2):179-193.

30. Roux PP, Blenis J. ERK and P38 MAPK-activated protein kinases: a family of protein kinases with diverse biological functions. Microbiol Mol Biol Rev. 2004;68(2):320-344.

31. Shih MH, Kao SC, Wang W, Yaster M, Tao YX. Spinal cord NMDA receptor-mediated activation of mammalian target of rapamycin is required for the development and maintenance of bone cancerinduced pain hypersensitivities in rats. J Pain. 2012; 13(4):338-349.

32. Manning BH, Mao J, Frenk H, Price DD, Mayer DJ. Continuous co-administration of dextromethorphan or MK-801 with morphine: attenuation of morphine dependence and naloxone-reversible attenuation of morphine tolerance. Pain. 1996; 67(1):79-88.

33. Mao J, Sung B, Ji RR, Lim G. Chronic morphine induces downregulation of spinal glutamate transporters: implications in morphine tolerance and abnormal pain sensitivity. J Neurosci. 2002; 22(18):8312-8323.

34. Ma W, Zheng WH, Kar S, Quirion R. Morphine treatment induced calcitonin gene-related peptide and substance $\mathrm{P}$ increases in cultured dorsal root ganglion neurons. Neuroscience. 2000;99(3):529-539.

35. Menard DP, et al. A calcitonin gene-related peptide receptor antagonist prevents the development of tolerance to spinal morphine analgesia. J Neurosci. 1996;16(7):2342-2351.

36. Boreddy SR, Pramanik KC, Srivastava SK. Pancreatic tumor suppression by benzyl isothiocyanate is associated with inhibition of PI3K/AKT/FOXO pathway. Clin Cancer Res. 2011;17(7):1784-1795.

37. Shim YJ, et al. Clusterin induces matrix metalloproteinase-9 expression via ERK1/2 and PI3K/ Akt/NF- $\mathrm{BB}$ pathways in monocytes/macrophages. J Leukoc Biol. 2011;90(4):761-769.

38. Johnston IN, et al. A role for proinflammatory cytokines and fractalkine in analgesia, tolerance, and subsequent pain facilitation induced by chronic intrathecal morphine. J Neurosci. 2004; 24(33):7353-7365.

39. Zhou D, Chen ML, Zhang YQ, Zhao ZQ. Involvement of spinal microglial $\mathrm{P} 2 \mathrm{X} 7$ receptor in generation of tolerance to morphine analgesia in rats. J Neurosci. 2010;30(23):8042-8047.

40. Raghavendra V, Tanga FY, DeLeo JA. Attenuation of morphine tolerance, withdrawal-induced hyperalgesia, and associated spinal inflammatory immune responses by propentofylline in rats. Neuropsychopharmacology. 2004;29(2):327-334.

41. Song P, Zhao ZQ. The involvement of glial cells in the development of morphine tolerance. Neurosci Res. 2001;39(3):281-286.

42. Choi JI, Svensson CI, Koehrn FJ, Bhuskute A, Sorkin LS. Peripheral inflammation induces tumor necrosis factor dependent AMPA receptor trafficking and Akt phosphorylation in spinal cord in addition to pain behavior. Pain. 2010;149(2):243-253.

43. Shi TJ, Huang P, Mulder J, Ceccatelli S, Hokfelt T. Expression of p-Akt in sensory neurons and spinal cord after peripheral nerve injury. Neurosignals. 2009; 17(3):203-212

44. Sun RQ, Tu YJ, Yan JY, Willis WD. Activation of protein kinase B/Akt signaling pathway contributes to mechanical hypersensitivity induced by capsaicin. Pain. 2006;120(1-2):86-96.

45. Xu JT, Tu HY, Xin WJ, Liu XG, Zhang GH, Zhai $\mathrm{CH}$. Activation of phosphatidylinositol 3-kinase and protein kinase $\mathrm{B} / \mathrm{Akt}$ in dorsal root ganglia and spinal cord contributes to the neuropathic pain induced by spinal nerve ligation in rats. Exp Neurol. 2007;206(2):269-279.

46. Xu Q, et al. Spinal phosphinositide 3-kinase-Aktmammalian target of rapamycin signaling cascades in inflammation-induced hyperalgesia. J Neurosci. 2011;31(6):2113-2124.

47. Kao SC, et al. Absence of mu opioid receptor mRNA expression in astrocytes and microglia of rat spinal cord. Neuroreport. 2012;23(6):378-384.

48. Horvath RJ, DeLeo JA. Morphine enhances microglial migration through modulation of $\mathrm{P} 2 \mathrm{X} 4$ receptor signaling. J Neurosci. 2009;29(4):998-1005.

49. King T, Ossipov MH, Vanderah TW, Porreca F, Lai J. Is paradoxical pain induced by sustained opioid exposure an underlying mechanism of opioid antinociceptive tolerance? Neurosignals. 2005; 14(4):194-205.

50. Liang DY, Li X, Clark JD. 5-hydroxytryptamine type 3 receptor modulates opioid-induced hyperalgesia and tolerance in mice. Anesthesiology. 2011; 114(5):1180-1189.

51. Little JW, et al. Spinal mitochondrial-derived peroxynitrite enhances neuroimmune activation during morphine hyperalgesia and antinociceptive tolerance. Pain. 2013;154(7):978-986.

52. Vanderah TW, et al. Tonic descending facilitation from the rostral ventromedial medulla mediates opioid-induced abnormal pain and antinociceptive tolerance. J Neurosci. 2001;21(1):279-286.

53. Ferrini F, et al. Morphine hyperalgesia gated through microglia-mediated disruption of neuronal $\mathrm{Cl}(-)$ homeostasis. Nat Neurosci. 2013; 16(2):183-192.

54. Al-Batran SE, Ducreux M, Ohtsu A. mTOR as a therapeutic target in patients with gastric cancer. Int J Cancer. 2012;130(3):491-496.

55. Geranton SM, et al. A rapamycin-sensitive signaling pathway is essential for the full expression of persistent pain states. J Neurosci. 2009;29(47):15017-15027.

56. Liaw WJ, Zhu XG, Yaster M, Johns RA, Gauda EB, Tao YX. Distinct expression of synaptic NR2A and NR2B in the central nervous system and impaired morphine tolerance and physical dependence in mice deficient in postsynaptic density-93 protein. Mol Pain. 2008;4:45.

57. Zhao X, et al. A long noncoding RNA contributes to neuropathic pain by silencing Kcna2 in primary afferent neurons. Nat Neurosci. 2013; 16(8):1024-1031. 